\title{
Victoria Park
}

\section{Nathanial Sharpley}

University of Technology Sydney, Faculty of Arts and Social Sciences, PO Box 123, Ultimo NSW 2007, Australia. nathaniel.sharpley@student.uts.edu.au

It was mid March this year when I visited Victoria Park. Not to say I hadn't visited before, walking through the park twice a week most weeks. This time however as a 'site visit' in its intentionality, the visit was of significantly greater educational substance. This visit, I joined most of the Aboriginal Political History student cohort in an excursion that almost felt like a walk back in time. With the purpose of gaining a larger understanding of Aboriginal occupation and use of the land which we use so regularly. That land being Victoria Park. A place that I was amused to feel a strange sense of nostalgia by the way we navigated the landscape.

The park for me and my personal use of the space had always been but a coincidental fragment in a journey to get somewhere else. This introductory week excursion was different with the opportunity to move beyond the perhaps Western mindset, and by that I mean being able to visualise the space in the much broader context of time than what is there today. To simply think that Victoria Park wasn't always the way it is today seems so basic and yet still

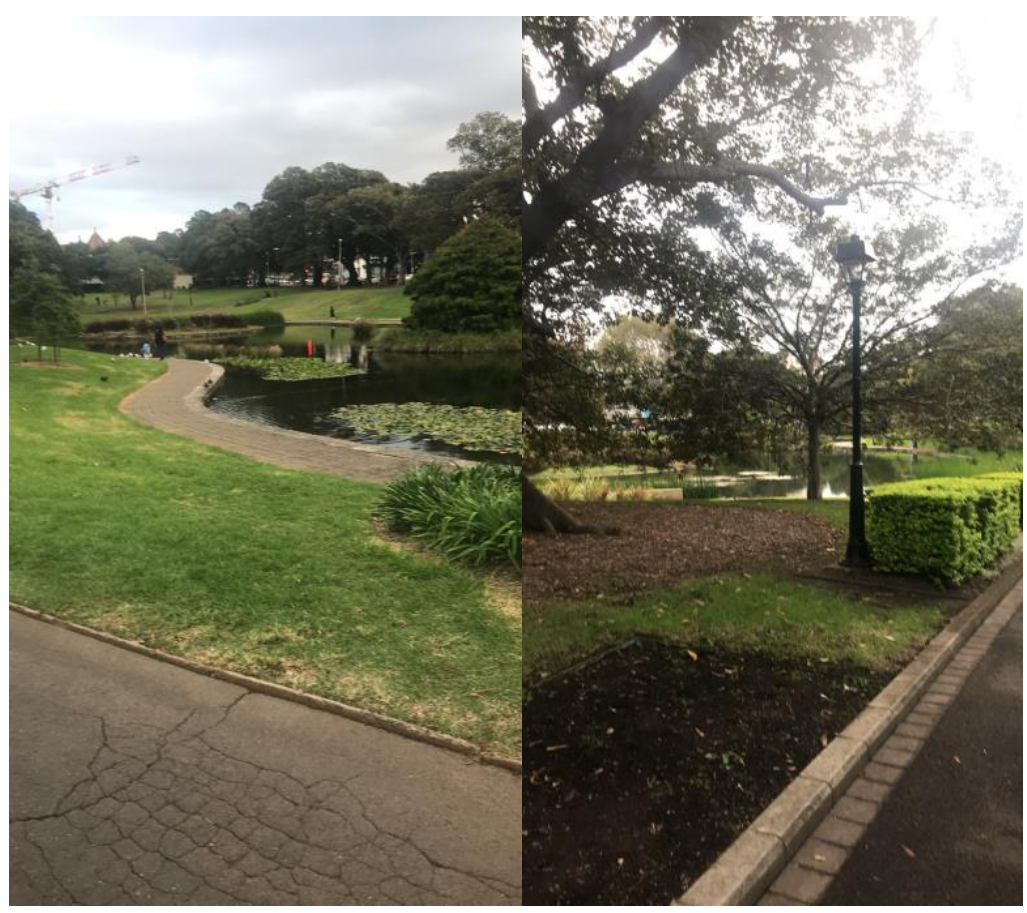
such an eye opening concept. The contours of the land partnered with my resurrected sense of time becomes the

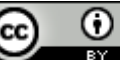
Attribution 4.0 Unported (CC BY 4.0) License (https://creativecommons.org/licenses/by/4.0/), allowing third parties to copy and redistribute the material in any medium or format and to remix, transform, and build upon the material for any purpose, even commercially, provided the original work is properly cited and states its license. 
dominant theme of this post because of the distant nostalgic feelings they generate. Many of the trees, the space, the flow of the land from overlooking hills to low lying lakes.

The feeling of the park's significance was ever-present just by its preserved nature as a green space in the CBD. In saying that, I had still looked at the park as a constructed space; not realising little things that were pointed out on the site visit. The water could symbolise so much. A timelessness flowing parallel with a now chaotic busy city. That lake was always there. As were the hills and grassy spaces. The hillier parts of the park would've made for a great resting point covered by big trees; whether that be fig trees providing food or paperbark trees with their own versatile uses. The eye-opener to all this visual stimuli was the potential for a very sustainable reality existing well before any colonial introduction. Reminders of 60000 years of history, of Gadigal people on this land. I highly recommend that when others visit Victoria Park, and so they should, that they do so with an openness towards a timeless imagination. For me, it now seems almost egotistical to view spaces like this across Australia without some level of inquisition into what once stood on this land and the contours of time that remain. Overall, it was a genuinely fulfilling experience.

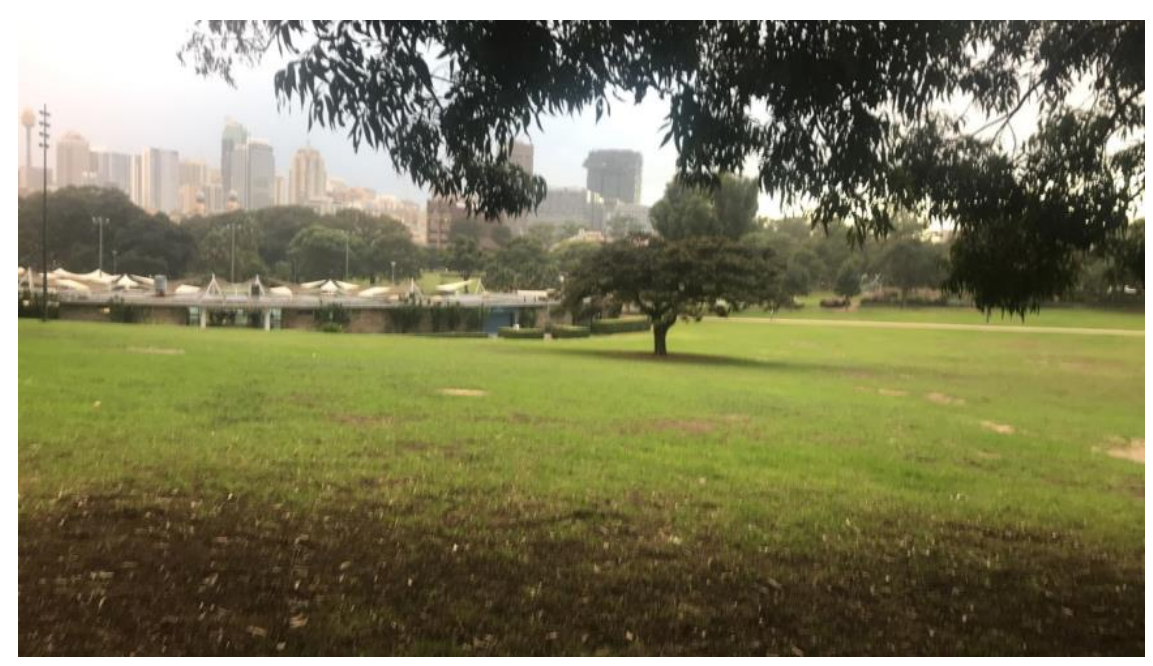

\section{References}

Barani: Aboriginal History, City of Sydney. http://bit.ly/2azVOBX 